Consejo Nacional de Población, Índices de inten sidad migratoria M éxico-Estados Unidos 2000, México, Consejo Nacional de Población, diciembre de 2002

\title{
Francisco Alba*
}

Este libro se suma a muchos otros del Consejo Nacional de Población en el cumplimiento, por parte del Conapo, del mandato que por ley tiene asignado: por un lado, proporcionar información confiable y ordenada en materia demográfica y, por otro, darle seguimiento riguroso a la problemática poblacional del país. El libro es obra de un equipo animado y presidido por el doctor Rodolfo Tuirán, anterior secretario del Consejo, quien es uno de los más reconocidos expertos mexicanos (dentro y fuera del país) en asuntos de migración internacional.

Conviene comenzar por mencionar la pertinencia y actualidad del contenido del libro. El gobierno de Fox emprendió un cambio cualitativo al hacer de la cuestión migratoria el eje central de las relaciones de México con Estados Unidos y conseguir, a partir de febrero de 2001, que se entablaran negociaciones migratorias entre los dos países. Este cambio desencadenó grandes, tal vez desmesuradas, expectativas entre la "nación mexicana" sobre una amplia solución a esta cuestión. Sin embargo, después del 11 de septiembre de 2001 se ha instalado el desencanto, aunque el clamor por negociar un acuerdo migratorio persiste como un legado de las negociaciones emprendidas, pareciendo no importar que el contexto para ello se haya vuelto muy desfavorable. Con posterioridad al 11 de septiembre, importantes grupos y actores políticos de Estados Unidos han enviado señales nada halagüeñas, solicitando que aun antes de reanudar las negociaciones migratorias, México debe estar dispuesto a emprender acciones sustantivas en materia de seguridad nacional y controles fronterizos para que los dos países se vuelvan a sentar alrededor de la mesa de negociaciones.

La demanda mexicana de un acuerdo tiende a ser sustentada en el hecho de que no se ha logrado modificar el conjunto de factores económicos y sociales que dinamizan el flujo masivo de mexicanos hacia aquel país, al tiempo que el propósito estadunidense de control

* Profesor-investigador del Centro de Estudios Demográficos y de Desarrollo Urbano de El Colegio de México. Correo electrónico: falba@colmex.mx 
y prevención del componente no autorizado de ese flujo, por medio de draconianas acciones de disuasión, se ha visto frustrado. Ello ha elevado los riesgos, incluido el de la muerte, para los migrantes que en su desesperación se echan en manos de traficantes sin escrúpulos. Se trata de un statu quo insostenible que ha pervivido por demasiado tiempo.

Las anteriores consideraciones no son ajenas al contenido de esta obra. El libro es y contiene mucho más que "índices de intensidad migratoria". Antes de llegar al capítulo "Geografía de la migración México-Estados Unidos", donde se sintetizan los resultados de estos índices, presenta un apretado pero completo y excelente resumen sobre "La migración México-Estados Unidos", donde pocos temas quedan sin ser tratados. Se describe el complejo sistema migratorio; se pasa revista a sus determinantes y principales explicaciones; se realiza un breve pero puntual ejercicio de prospectiva, donde se subraya que las tendencias migratorias futuras dependerán en gran medida del "derrotero regional" del patrón de desarrollo mexicano, y de la consolidación de centros urbanos que se vuelvan polos alternos de atracción para los potenciales migrantes internacionales.

Se retoma de esa revisión un par de consideraciones que constituyen una imagen esclarecedora sobre el panorama actual y la perspectiva inmediata del fenómeno migratorio. Es aceptado que si hay una "solución" a la migración masiva, ésta subyace, en gran parte, en un desarrollo económico extenso y amplio de los lugares de origen (desarrollo, en alguna medida, "conmensurable" con el del país de destino). Sin embargo, en el corto plazo, en la experiencia concreta mexicana, el patrón de desarrollo que se está generando con la liberalización comercial - fenómeno ineludible y potenciador importante del crecimiento económico- ha producido aún más migración; entre otras razones, por los sesgos del proceso, por no atender a las fuerzas reales de la economía, y por el rezago educativo, científico y de innovación tecnológica del país. (El libre comercio no garantiza que el país lleve a cabo esas tareas impostergables en el contexto de un mundo sometido a transformaciones globales con economías y sociedades abiertas.)

Tuirán y su equipo muy atinadamente sostienen que los efectos de la migración mexicana dependen de la escala y las modalidades de la misma. La escala, añado yo, es masiva; y las modalidades apuntan a que la emigración se convertirá gradual, pero sostenidamente, en un proceso cada vez más costoso para el país — por contar los migrantes 
con un capital humano cada vez más valioso, pero por proyectar la realización de sus sueños y ambiciones en otras tierras (aunque no olvidan sus raíces, ni pierden del todo sus esperanzas en la tierra propia, a la que han enviado generosamente miles de millones de dólares, año tras año).

La heterogeneidad y complejidad de los flujos migratorios de mexicanos es un rasgo reconocido, como lo es su diversificación regional, incluida su progresiva expansión hacia las zonas urbanas. Los índices de intensidad migratoria nos permiten, en una primera instancia, conocer y analizar el fenómeno migratorio y su dinámica; en una instancia ulterior (cruzando los índices con otras variables) se amplían las posibilidades de su explotación, por analistas y estudiosos, para la elaboración de explicaciones y ejercicios de prospectiva.

El índice de intensidad migratoria se construye a partir de datos de los hogares, utilizando para ello la muestra de $10 \%$ del XII Censo de Población y Vivienda de 2000. El índice "combina" y pondera datos sobre hogares en los que, en el periodo de referencia (1995-2000), salió o hubo algún migrante circular, regresó algún migrante, algún miembro del hogar residía en Estados Unidos, y (o) el hogar recibió remesas. Conviene observar que las correlaciones entre estas cuatro variables alcanzan valores muy altos, tanto en el ámbito estatal como en el municipal. Con este libro se pone a disposición de la comunidad de especialistas y del público en general una gran riqueza de información. Además, a tono con una sociedad de la informática, con demandas de transparencia y libre acceso a la información gubernamental, se incluye un disquete que permite utilizar esta información de acuerdo con los intereses de los usuarios más diversos. En el libro se describe la metodología seguida, misma que puede ser evaluada o replicada en caso pertinente. Los índices se calculan a nivel estatal y a nivel municipal, lo que no es asunto menor.

Ciertamente, los índices ofrecen una fotografía, captan la situación en un momento determinado (los años previos al 2000); sin embargo, las consideraciones analíticas que anteceden su presentación enriquecen el sentido de la información que ahora se hace disponible. En un contexto analítico, inteligente, los índices permiten avanzar en las respuestas a preguntas que siguen abiertas: las relaciones entre desarrollo y migración; los efectos de la migración sobre el desarrollo; las relaciones entre pobreza o marginación y migración. De hecho, en el libro se realizan tres ejercicios analíticos (que pueden servir como ejemplo del potencial que ofrece la utilización de 
estos índices puestos en relación con un gran número de variables en modelos conceptuales y estadísticos pertinentes).

Así, en el primero de ellos no se encontró una relación sistemática entre marginación a escala municipal y migración a Estados Unidos; de los 386 municipios con grado de marginación muy alto, sólo 26 tienen una intensidad migratoria alta o muy alta, al tiempo que uno de cada cinco municipios con grado de marginación alto registra una intensidad migratoria alta o muy alta: sólo 184 de 906 municipios. En el segundo se confirmó, en términos generales, que los migrantes ni son mayoritariamente personas en situación de pobreza, ni provienen ante todo de las zonas en condiciones de pobreza severa; de los 374 municipios con grado de severidad de pobreza muy alto, sólo 49 tienen una intensidad migratoria muy alta o alta, mientras que casi dos de cada tres registran una intensidad migratoria muy baja o baja; por su lado, de los 388 municipios con grado medio de severidad de pobreza, 118 registran una intensidad migratoria muy alta y alta, 64 observan una intensidad media, y 197 tienen una intensidad migratoria muy baja y baja. En el tercero se constató la relativamente escasa participación de los municipios indígenas en el fenómeno migratorio; de los 346 municipios indígenas —donde la población de cinco años de edad o más que habla lengua indígena representa al menos $70 \%$ de la población total-, sólo 30 muestran una intensidad migratoria hacia Estados Unidos muy alta o alta; en cambio, 230 municipios indígenas registran una intensidad migratoria baja o muy baja.

En relación con la cuestión de las continuidades y los cambios del fenómeno migratorio - cuestión que sigue siendo objeto de gran debate en cuanto al significado e implicaciones de esos cambios y continuidades-, los índices a nivel estatal arrojan resultados interesantes, aunque esperados. Los estados con un índice de intensidad migratoria muy alto —Zacatecas, Michoacán, Guanajuato, Nayarit y Durango- se traslapan con los estados que tradicionalmente han sido de origen de los migrantes. Algunos estados con un alto índice -Aguascalientes, Jalisco, Colima y San Luis Potosí- también coinciden con estados tradicionales; pero los índices altos también se exhiben ya en algunos estados emergentes, como Morelos, Guerrero e Hidalgo.

En cambio, los índices de intensidad migratoria a nivel municipal muestran con toda claridad la gran heterogeneidad y dispersión territorial del fenómeno migratorio (los rangos de este índice a nivel 
municipal son mucho más amplios que a nivel estatal). Así, hay municipios con muy altos índices que pertenecen no sólo a estados tradicionalmente emisores de migrantes, sino también a algunos estados emergentes, como Guerrero, Oaxaca y Puebla (la Mixteca). De manera similar, algunos municipios con altos índices se ubican también en estados como Hidalgo, Querétaro, Estado de México y Nuevo León, que se hallan fuera de las regiones tradicionales. También se constata que son sólo unas pocas decenas los municipios que no registran algún tipo de actividad migratoria puesta en operación por cualquiera de las cuatro variables componentes del índice.

Ciertamente no poseemos un indicador equiparable a este índice para fechas pasadas a fin de examinar cambios en el largo plazo del fenómeno migratorio. Sin embargo, más allá de las múltiples controversias al respecto, estos índices muestran que es indudable que el fenómeno migratorio se ha ido extendiendo a lo largo y ancho del país — con intensidad variable, desde luego-, al punto que hay pocos sitios del territorio, sean éstos localidades o municipios, que no experimenten algún vínculo migratorio. Esta realidad, y su previsible permanencia en el mediano y largo plazos, obligan al gobierno y a la sociedad mexicanos a continuar haciendo del fenómeno migratorio y de la cuestión migratoria un asunto central, tanto de la política exterior como de la interna.

La tarea no es nada fácil. En el contexto posterior al 11 de septiembre, la obtención de un acuerdo migratorio amplio difícilmente se dará sin contrapartidas potencialmente costosas para México. La contaminación de las agendas de seguridad y migración (no necesariamente de los temas) es un hecho. Si anteriormente era conveniente y deseable contar con una política migratoria integral y congruente —respecto a la emigración, el tránsito y la inmigración al país-, en la actualidad ello es necesario e imprescindible si se quiere tener algún orden de prioridades y un sentido de dirección de hacia dónde se quiere que el país transite en el largo plazo. Si se tuviera una visión clara, compartida en forma amplia por la sociedad, del lugar de México en los procesos de integración regional, hacia el norte y hacia el sur, los pequeños pasos que pudieran darse hacia un ordenamiento de la migración tendrían sentido; sin una visión consensuada el desorden difícilmente permitiría el avance de una agenda mexicana.

El país requiere verse a sí mismo con realismo. Si bien es cierto que las fuerzas de la demanda laboral de la economía estadunidense son poderosísimas y muy atractivas, la economía y la sociedad 
mexicanas han estado funcionando deficientemente por muy largos periodos, al punto de favorecer esta continuada, sostenida y creciente emigración masiva de nacionales. El desarrollo del país tiene inmensas fallas estructurales que es urgente corregir. Con recursos propios, y (o) con recursos externos, el país debe hacer de la búsqueda de la convergencia económica regional (desde una perspectiva pluridimensional) un objetivo nacional ordenador de decisiones. En la tarea de descubrir los complejos nexos entre el desarrollo y la migración - conocimientos que enriquecen la toma de decisiones-, la información contenida en este libro - y en su disquete-constituye una valiosa y fructífera herramienta. 